\title{
Developed Equation For Fitting ASTM Distillation Curves
}

\author{
Dr. Khalid Farhod Chasib \\ Chemical Engineering Department - University Of Technology
}

\section{$\underline{\text { Abstract }}$}

\section{The present work deals}

with fitting literature data of ASTM Distillation curves and obtain a new correlation suitable to use in modeling when optimizing the refining processes, such as distillation, FCC, catalytic reforming, hydrotreating, etc.

The results showed that the values predicted by a new correlation are very good agreement with data of literature and the range of mean overall deviation (\%MOD) is $(0.305-0.585)$.

Keywords: Distillation curves, ASTM, Refining Processes.

\section{$\underline{\text { Introduction }}$}

Distillation curves provide a breadth of information about the crude oil or the petroleum fuel. In certain respects, the boiling point distribution is representative to the composition of the petroleum fraction. Therefore, in principle, by determining the presence and volume percent of the components in a conventional hydrocarbon fuel solution, the overall physical properties can be determined ${ }^{(1)}$.

The simple distillation curve is the temperature as a function of the percent distilled in a simple or Rayleigh type of distillation. This type of distillation is approximated by the laboratory A.S.T.M. distillation which is widely used to 
characterize petroleum fractions.

The A.S.T.M. procedure gives some reflux and rectification, and the results are not exactly equal to the simple batch distillation, although the difference is not large. The temperature normally measured is the condensation temperature of the vapor flowing from the still to the condenser $^{(1)}$.

There are many types of standard distillation tests that determine the boiling point distribution of petroleum fuels, the interconversion between which is well documented. Some of the more common standard test methods for distillation of petroleum products include: ASTM D86-96, which is performed under atmospheric pressure and is used for determining the boiling point distribution of light petroleum fractions, such as naphtha, kerosene, diesel, and light gas oil; micro-distillation; molecular distillation; fractional distillation (typically using a spinning band still); ASTM D5236 distillation (typically using a pot still); D1160 (for heavy petroleum fractions); ASTM D3710 (simulated distillation, which is also known as the GC SimDist method, and uses gas chromatography to determine the true boiling point, or TBP, of gasoline); ASTM D2887 (GC SimDist to determine the TBP of petroleum fraction other than gasoline); ASTM D2892 (also known as 15/5 distillation, which produces simulated TBP of petroleum fuels using a distillation column with 15 theoretical plates and a reflux ratio of 5); ASTM D5236 Distillation (also known as the vacuum pot still method, and is used for heavy hydrocarbon mixtures); ASTM D5307 (SimDist for determining TBP of crude oil); ASTM D6352-98; and Hemple analysis for the distillation of a large volume of fuel samples providing further detailed analysis of the produced distilled cuts. 
ASTM D86-96 and D1160 may be combined together for determining the boiling point distribution of wide boiling range materials, such as crude oils ${ }^{(2)}$.

ASTM Distillation tests for gasoline, naphtha (A naphtha is a volatile petroleum fraction, usually boiling in the gasoline range), and kerosene (D86); natural gasoline (D216); and gas oil (D158) involve much the same procedure. A somewhat similar test known as the "Engler distillation" has been used in the past, and often the ASTM distillation is referred to as "an Engler" (2).

The ASTM distillation curve conducted on the whole crude. This type of distillation curve is used however on a routine basis for plant and product quality control. This test is carried out on crude oil fractions using a simple apparatus designed to boil the test liquid and to condense the vapors as they are produced. Vapor temperatures are noted as the distillation proceeds and are plotted against the distillate recovered. Because only one equilibrium stage is used and no reflux is returned, the separation of components is poor and mixtures are distilled $^{(3)}$.

The molecular distillation process $(4,5)$ introduces a potential technique for attainment of liquid volume percentage in relation to temperature for the distilled fractions. In Batistella ${ }^{(6)}$, it can be verified the robustness of this method since it enables operation at low temperatures, short residence times, being ideal for working with high molecular weight and thermally sensitive compounds ${ }^{(7)}$. In the petroleum case, avoids thermal cracking, allowing, thus, the development of a methodology for determination the real TBP curve. The molecular distillation technique has being reported. It is necessary, however, establish a relationship between the operating conditions of 
the molecular distiller and the TBP curve $^{(8,9)}$. In Batistella et al. ${ }^{(10)}$, data of temperature and percentage of distillate from molecular distiller, obtained experimentally, were used in the TBP curve extension, and a new correlation

(FRAMOL correlation) was presented ${ }^{(11)}$ :

$$
T B P=456.4+0.1677 \times T_{D M}+1.64 \cdot 10^{-4} \times T_{D M}^{2}+4.13 \cdot 10^{-6} \times T_{D M}^{3}
$$

where: $T B P=$ True Boiling Point $\left({ }^{\circ} \mathrm{C}\right)$;

$T_{D M}=$ Operating temperature of the Molecular Distiller $\left({ }^{\circ} \mathrm{C}\right)$.

Fitting Of Astm Distillation Data

In order to develop a correlation for certain thermodynamic property, one has to determine all the parameters that influence this property and then studies the influence of each of these parameters on the property under consideration, using literature data available for this purpose ${ }^{(12)}$.

In the past five decades the researchers tried to calculate the properties of crude oil or the petroleum fuel by making a mathematical model, which is a function of composition and some constants, which fits the experimental data. This mathematical model is not supported by any theoretical base. With the development of computer and computer programs the use of analytical expressions to interpolate, extrapolate and even predict thermodynamic information has become of increasing importance for process design and for modeling of process operation ${ }^{(13)}$.

ASTM Distillation curves of refining fractions can be adequately described by an empirical equation. 
The equation is suitable for insertion in models used for optimizing operation of refining processes such as distillation, FCC , catalytic reforming, hydrotreating , etc. the equation takes the form of:

$V=\left\{1-e^{-\left(\frac{\Psi}{\alpha}\right)^{\beta}}\right\} \times 100$

where $V$ is the volume percent distilled at temperature $T$ and $\alpha$ and $\beta$ are constants and determined from the data of ASTM distillation curve, $\Psi$ is the dimensionless temperature defined as:

$\Psi=\frac{T-T_{i}}{T_{f}-T_{i}}$

where $T_{i}$ and $T_{f}$ are the initial and final boiling point temperatures of ASTM distillation respectively. By defining dimensionless temperature $\Psi$, the constant of Eq.2 are invariant with respect to unit of temperature.

\section{Maximum-Likelihood Principle}

The estimation of parameters in theoretical and semiempirical mathematical models from experimental data is an important requirement in many fields of science and engineering. In the maximum-likelihood analysis, it is assumed that all measured data are subject to random errors. If each experiment were replicated, the average value for each replicated experimental point would approach some true value. Usually the distribution of a measured variable about its true value is approximated by the normal distribution, characterized by an associated variance. The variances are ideally obtained from replicated experiments, but they may be estimated from experience associated with a particular type of experimental apparatus. It is customary to assume that the random errors in different. 
For each experiment, the true values of the measured variables are related by one or more constraints. Because the number of data points exceeds the number of parameters to be estimated, all constraint equations are not exactly satisfied for all experimental measurements. Exact agreement between theory and experiment is not achieved due to random and systematic errors in the data and to "lack of fit" of the model to the data. Optimum parameters and true values corresponding to the experimental measurements must be found by satisfaction of an appropriate statistical criterion ${ }^{(14)}$.

If this criterion is based on the maximum-likelihood principle, it leads to those parameter values that make the experimental observations appear most likely when taken as a whole. The likelihood function is defined as the joint probability of the observed values of the variables for any set of true values of the variables, model parameters, and experiments are uncorrelated ${ }^{(14)}$. error variances. The best estimates of the model parameters and of the true values of the measured variables are those which maximize this likelihood function with a normal distribution assumed for the experimental errors ${ }^{(14)}$.

The parameter estimation algorithm based on the maximum likelihood principle, converges rapidly for almost any initial estimates of the parameters. The rapid convergence is due in part to the similarity to Gauss-Newton method and in part to the successful application of a step-limiting procedure that assures superior convergence behavior ${ }^{(15)}$.

The maximum likelihood principle method provides a mathematical and computational guarantee of global optimality in parameter estimation that provides the best fit to measured data ${ }^{(15)}$. The objective function in nonlinear parameter estimation problems is given by equation (4). 


\section{Determination Of Constants}

Constants $\alpha$ and $\beta$ are calculated such that Eq.2 fits the literature data ${ }^{(1,2)}$ of ASTM distillation. The properties of the crude oils and petroleum fractions used are shown in Table (1). To obtain the best fitting that describe the ASTM curves, the sum of square of errors for prediction should be minimum. Let $T_{1}, T_{2}, \ldots, T_{n}$ and $V_{l}$, $V_{2}, \ldots, V_{n}$ be the data of ASTM distillation test. The values of $\alpha$ and $\beta$ should minimize the following function:

$$
F=\sum_{i=1}^{n}\left[\left\{1-e^{-\left(\frac{\Psi}{\alpha}\right)^{\beta}}\right\} \times 100-V_{i}\right]^{2}
$$

Table 1 The properties of the crude oils and petroleum fractions

\begin{tabular}{|c|c|c|c|c|c|}
\hline Type of ASTM distillation curve & $\begin{array}{l}\text { Type of crude oil or } \\
\text { petroleum fractions }\end{array}$ & $\begin{array}{c}\text { API } \\
\text { Gravity }\end{array}$ & $\begin{array}{l}T_{i}, \\
{ }^{\circ} \mathrm{C}\end{array}$ & $\begin{array}{l}T_{f}, \\
{ }^{\circ} \mathrm{C}\end{array}$ & $\begin{array}{l}\text { Ref. } \\
\text { No. }\end{array}$ \\
\hline Feed to FCC unit & $\begin{array}{l}\text { Lindsey Oil Refinery, } \\
\text { CFP/FINA, Englang }\end{array}$ & 27.6 & 325 & 595 & 2 \\
\hline Gasoline from FCC unit & $\begin{array}{l}\text { Lindsey Oil Refinery, } \\
\text { CFP/FINA, Englang }\end{array}$ & 16.6 & 102 & 214 & 2 \\
\hline LCO from FCC unit & $\begin{array}{l}\text { Lindsey Oil Refinery, } \\
\text { CFP/FINA, Englang }\end{array}$ & 15.3 & 196 & 349 & 2 \\
\hline LCO and slurry from FCC unit & $\begin{array}{l}\text { Lindsey Oil Refinery, } \\
\text { CFP/FINA, Englang }\end{array}$ & 9.1 & 280 & 530 & 2 \\
\hline Arabian Heavy Crude Oil & Safaniya, Saudi Arabia & 27.4 & 20 & 850 & 1 \\
\hline Arabian Light Crude Oil & $\begin{array}{c}\text { Beri, } \\
\text { Saudi Arabia }\end{array}$ & 33.4 & 20 & 810 & 1 \\
\hline
\end{tabular}


The problem of minimization is non-linear optimization, and an analytical solution is difficult to obtain. A numerical method, employing the maximum-likelihood principle technique, has been developed to resolve the above problem. In this numerical method, the function $F$ is minimized with respect to $\alpha$ and $\beta$. The procedure of the numerical method is complex and is not discussed here.

A computer program was designed and developed by using Matlab software for the purpose of this work. The basic design structure involves modularized procedures or subroutines to facilitate testing and development. The whole structure of the computer program was subjected to numerous tests and debugging procedures, and was only completed after undergoing many developments to optimize calculation procedures. The flow chart of computer program illustrated schematically in figure (1).

\section{Statistical Measurement And}

\section{Analysis Of Dispersion}

The applicability and accuracy of any proposed correlation it is very important to know how this correlation fits the literature data which is done by comparing the obtained results from the proposed correlation with the literature data.

The various measurement of dispersion or variation are available, the most common being the Mean Overall Deviation.

The percentage of Mean Overall Deviation "\% MOD" is a more tangible element indicating the overall goodness of the fit of the data by the correlation and it defines as (14):

$\% M O D=\frac{\sum_{i=1}^{n}\left|\frac{M_{i}^{\text {lit. }}-M_{i}^{\text {calcd }}}{M_{i}^{\text {lit. }}}\right|}{n} \times 100$ 
where $M$ is an intensive property and $n$ is the number of literature data point.

\section{$\underline{\text { Results And Discussion }}$}

$\mathrm{P}_{\text {etroleum is evaluated }}$ mainly in terms of its ASTM distillation curve, what makes possible to investigate the yields of the products that will be obtained in the refineries, as well as to establish operational strategies and process optimization.

ASTM distillation curves are drawn for each blend component, with the temperature on the vertical axis (Y-axis) and the volume percent distilled on the horizontal axis (Xaxis). Distillation must be on a consistent basis for all components; that is, either percent evaporated or percent recovered.

The temperature at any point is the averaged result of a large number of components and includes all the effects of non-ideality in the solutions. Thus in most cases it is impossible to relate such a curve to the volatility of the individual components involved. As a result, such simple distillation curves are not of much direct value for the solution of rectification problems.

As shown in Figs. 2 to 7 , the numerical method successfully fits Eq. 2 to ASTM distillation data of the feed and products of FCC unit and for Crude Oil. The Mean Overall Deviation "mean $D \%$ " for all ASTM distillation curves is very small which reflect the agreement between prediction and literature data as illustrated in table 2. 


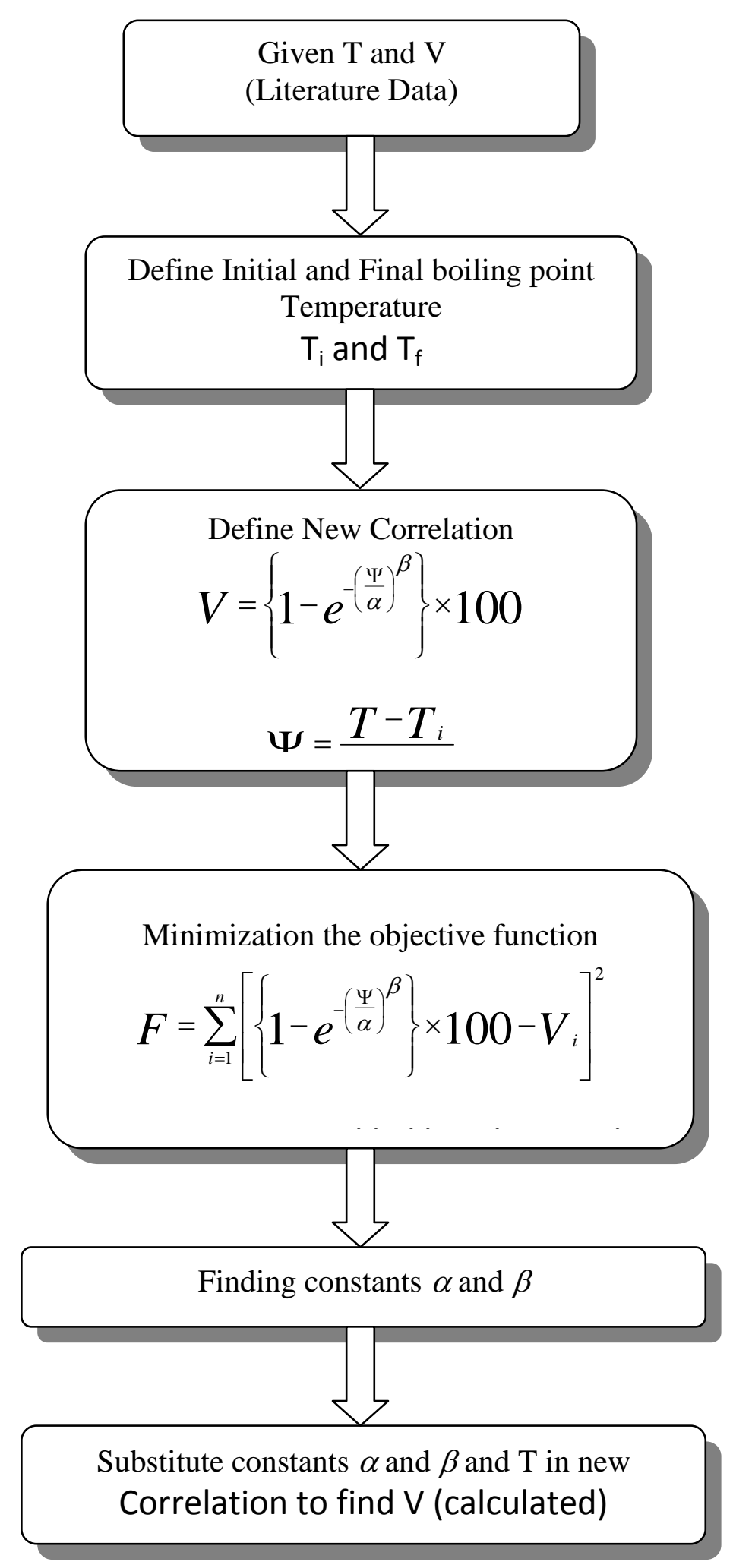

Fig. (1) The flow chart of computer program 


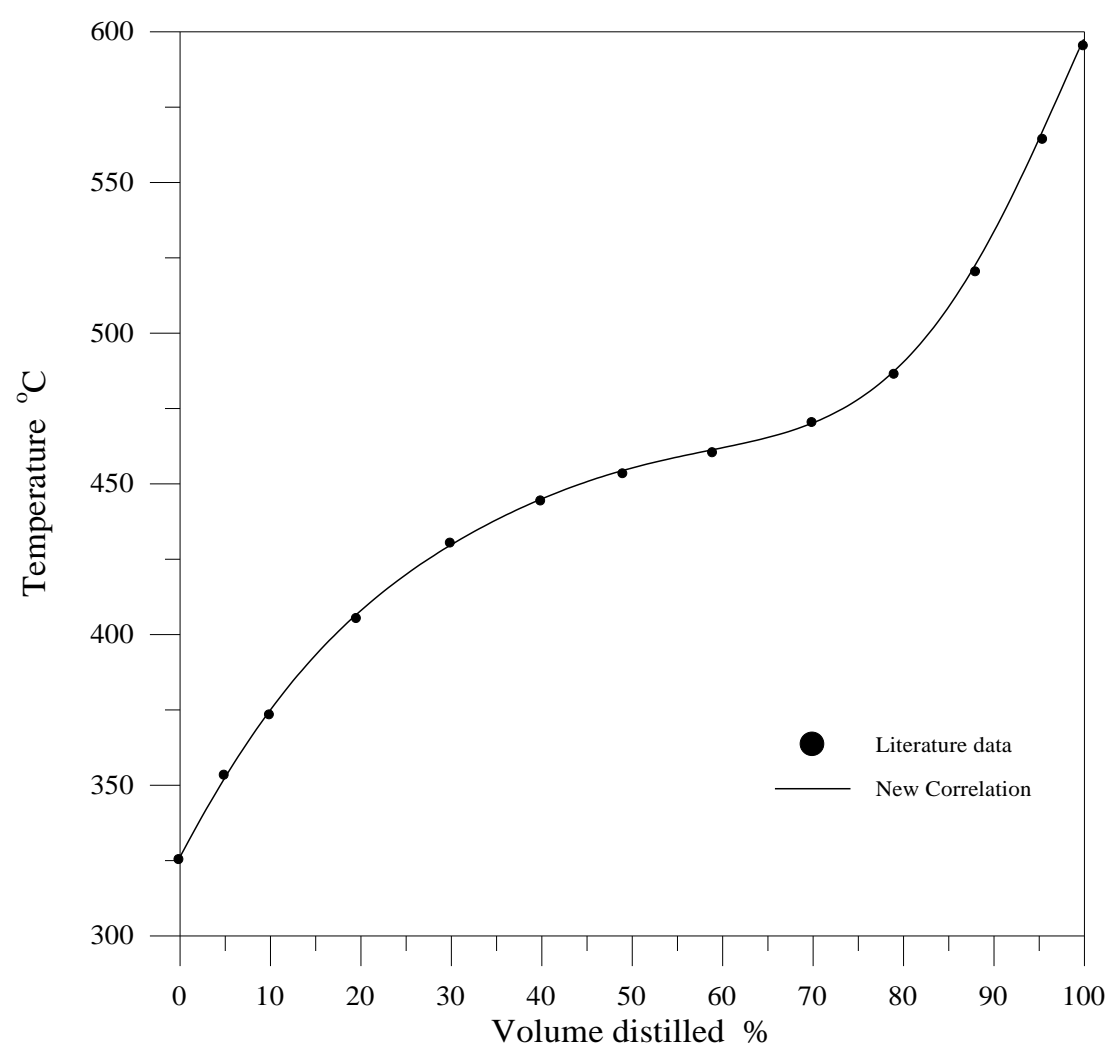

Fig.(2) ASTM distillation curve for feed to FCC unit

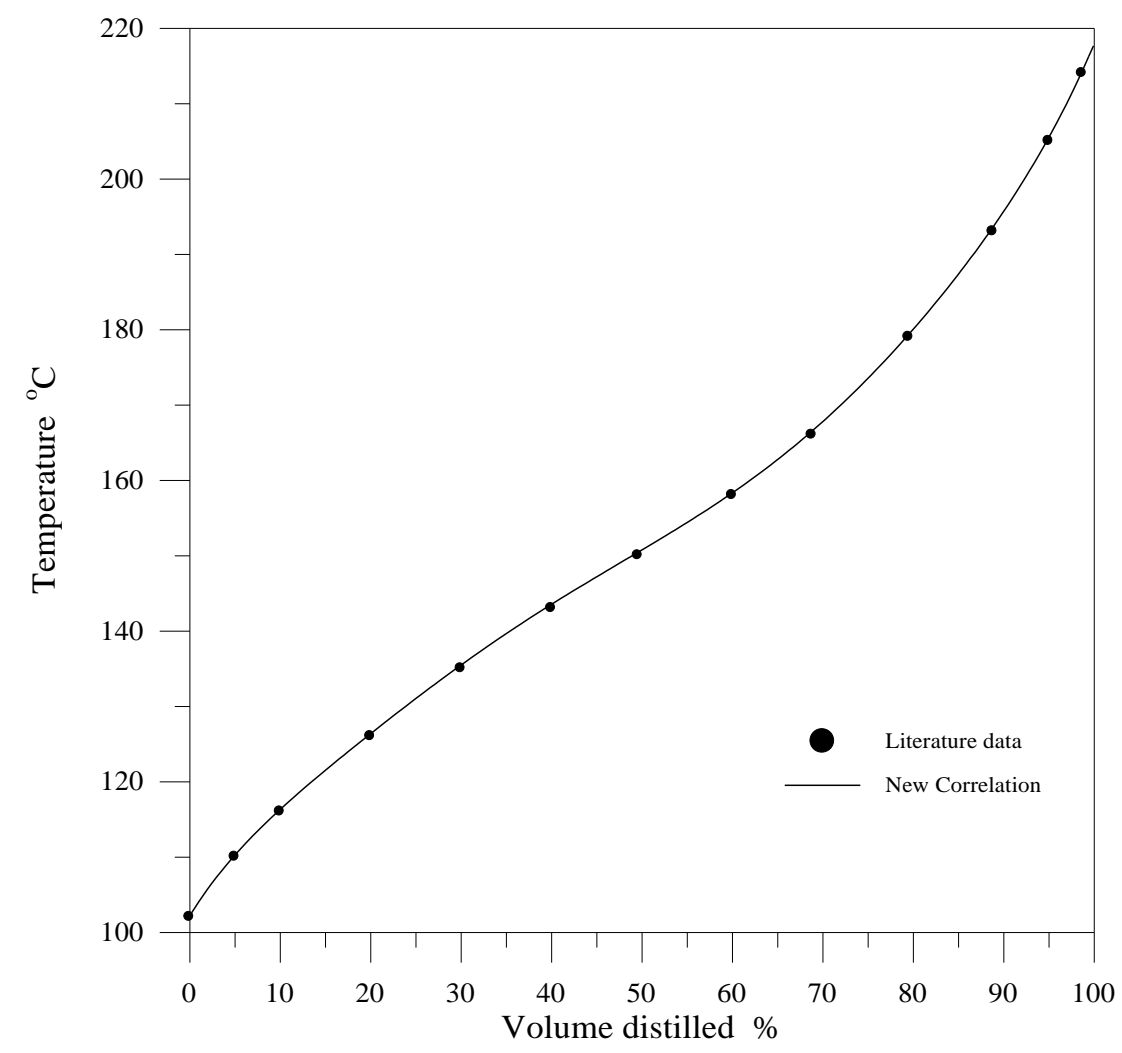

Fig.(3) ASTM distillation curve for gasoline from FCC unit 


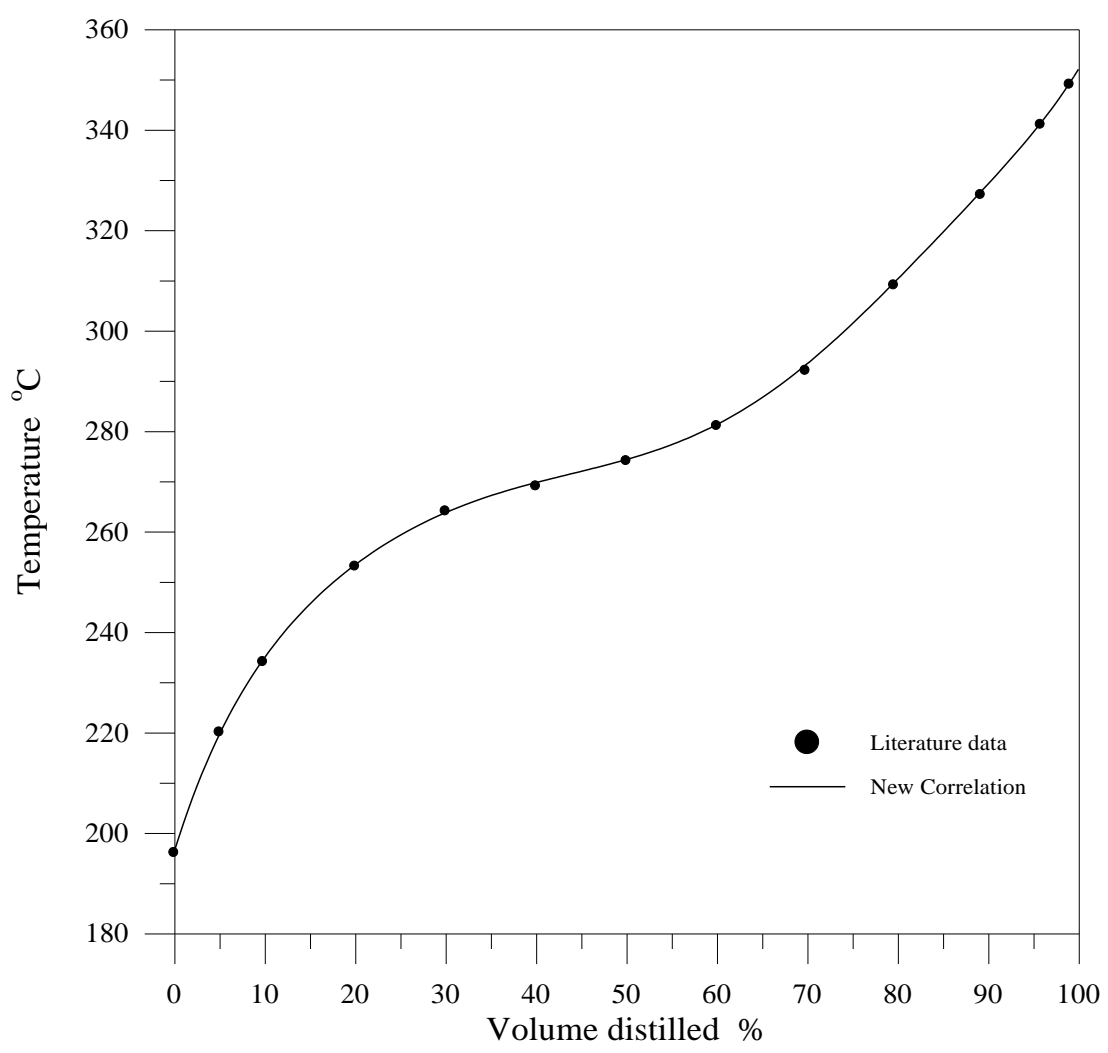

Fig .(4) ASTM distillation curve for LCO from FCC unit

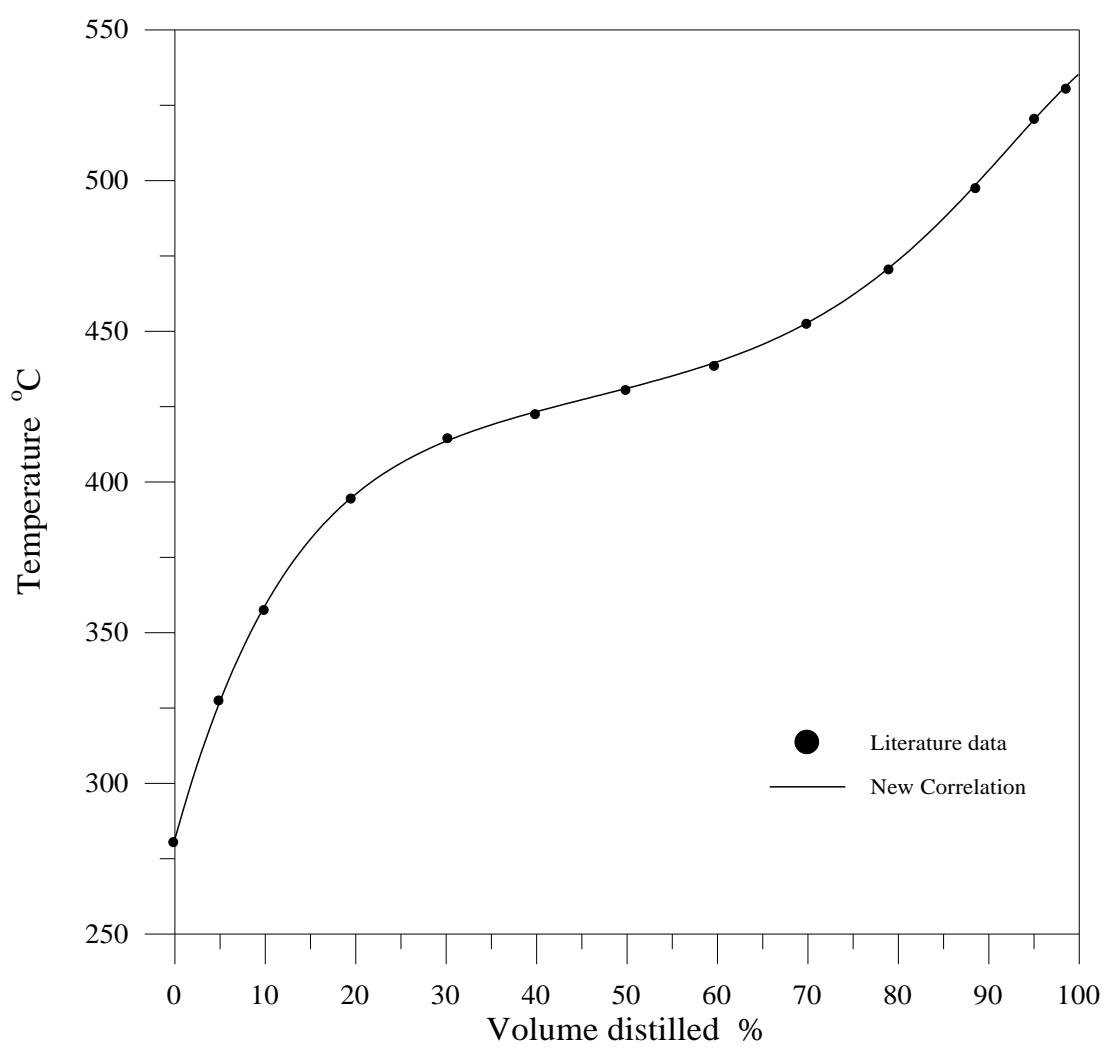

Fig.(5) ASTM distillation curve for mixed product of LCO and slurry from FCC unit 


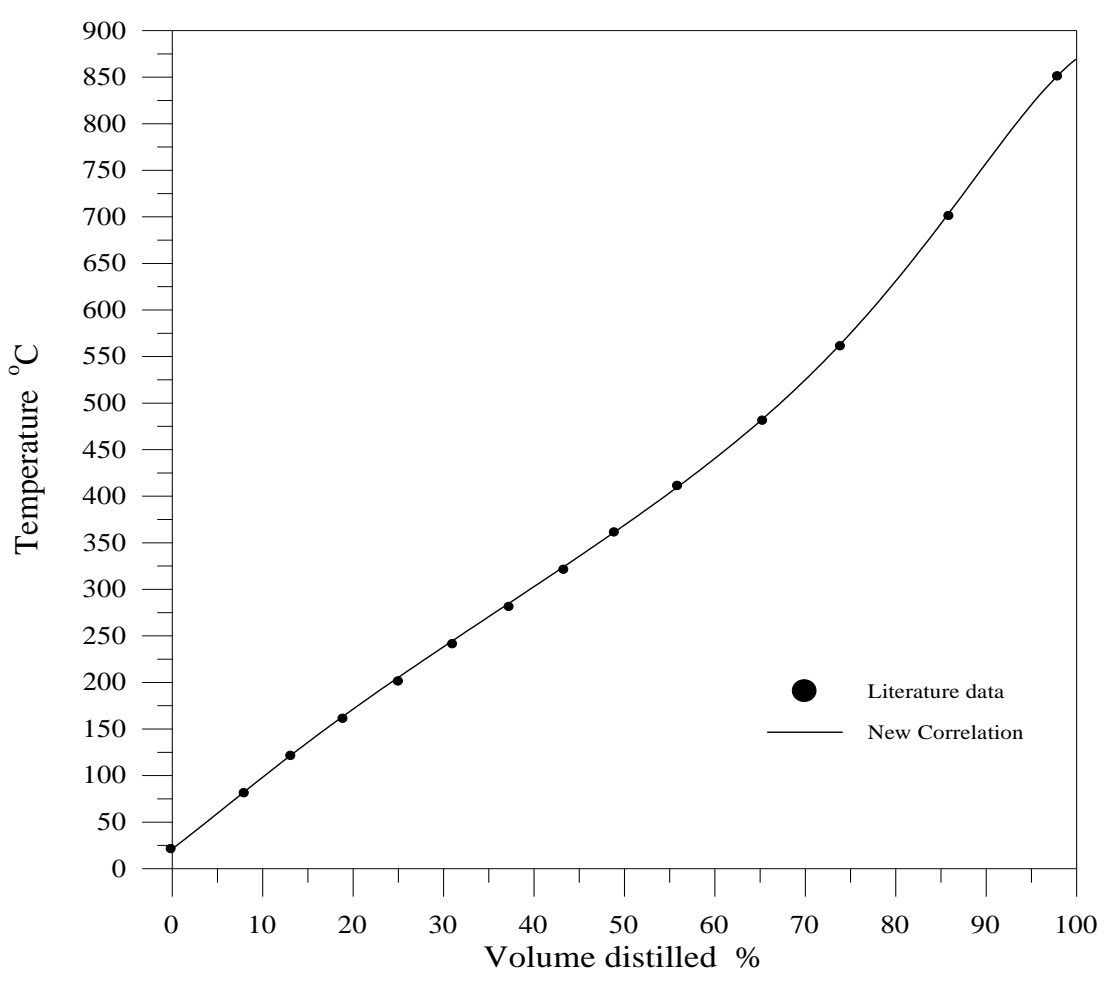

Fig.(6) ASTM distillation curve for Arabian Heavy Crude Oil

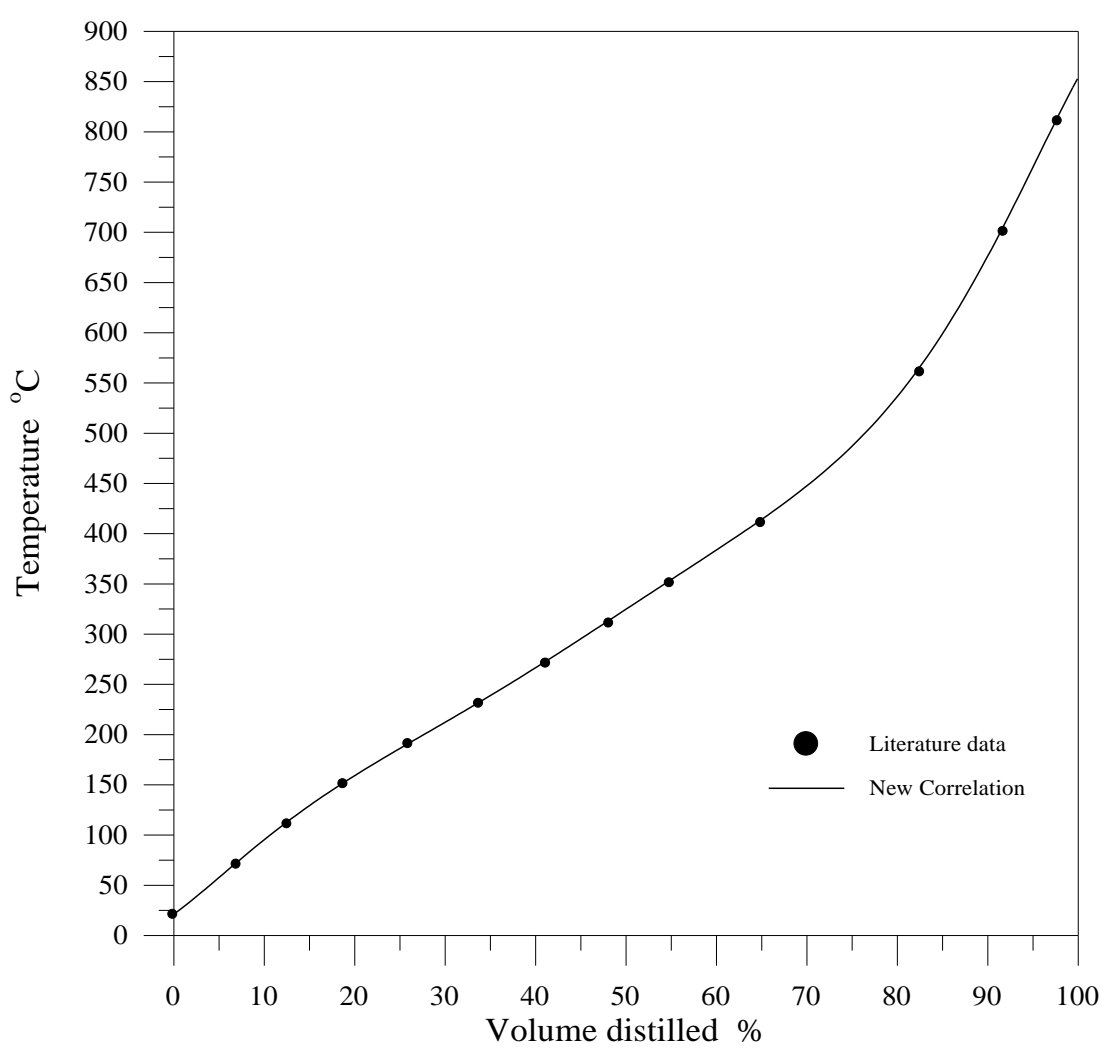

Fig .(7) ASTM distillation curve for Arabian Light Crude Oil 
Table (2) Optimum values of constants $\alpha$ and $\beta$ and percentage of Mean Overall Deviation

\begin{tabular}{|c|c|c|c|}
\hline Type of ASTM distillation curve & $\boldsymbol{\alpha}$ & $\boldsymbol{\beta}$ & \% MOD \\
\hline Feed to FCC unit & 0.591 & 2.925 & 0.476 \\
\hline Gasoline from FCC unit & 0.592 & 1.804 & 0.305 \\
\hline LCO from FCC unit & 0.622 & 2.722 & 0.368 \\
\hline LCO and slurry from FCC unit & 0.683 & 3.296 & 0.403 \\
\hline Arabian Heavy Crude Oil & 0.601 & 1.764 & 0.585 \\
\hline Arabian Light Crude Oil & 0.599 & 1.798 & 0.514 \\
\hline
\end{tabular}

\section{Conclusions}

\section{The properties of natural}

petroleum and petroleum products make use of the ASTM distillation analyses very useful for petroleum characterization, design and operation of refinery units, the classification of petroleum, the development of petroleum property correlations and it has been used worldwide. Optimum values of constants $\alpha$ and $\beta$ are significantly different for each case (Figs. 2 to 7 ).
Eq. 2 has been successfully integrated in model of FCC Unit for blending ASTM distillation curves of fresh feed, recycle LCO and recycle $\mathrm{HCO}$ for the total feed to the reactor. 


\section{$\underline{\text { References }}$}

1. W. C. Lyons, (1996), Standard Handbook of Petroleum and Natural Gas Engineering, Gulf Publishing Company.

2. J. G. SPEIGHT, (2002), Handbook of Petroleum Product Analysis, John Wiley \& Sons, Inc., Hoboken, New Jersey.

3. R. J. HENGSTEBECK. (2001), PETROLEUM PROCESSING, Principles and Applications, the McGraw-Hill Book Company, Inc.

4. Wolf, F. R. E Maciel, M. R. W., (2001), Project $n^{\circ}$ 1, UNICAMP / FUNCAMP / FNDCT/CTPETRO / PETROBRAS / FINEP.

5. Wolf, F. R. E Maciel, M. R. W, (2004), Project $\mathrm{n}^{\circ}$ 2, UNICAMP / FUNCAMP / FNDCT/CTPETRO / PETROBRAS / FINEP.

6. Batistella, C. B., (1999), PHD Thesis (in Portuguese), UNICAMP, SP, Brazil.

7. Batistella, C. B. E Maciel, M. R. W., (1998), Comput. Chem. Eng., v. 22, S53-S60.

8. Burrows, G,(1960), Molecular Distillation. Oxf. Univ. Press (Oxford) .

9. Boduszynski, M.M E Altgelt, K.H., (1994), Composition end Analysis of Heavy Petroleum Fractions. Marcel Dekker, Inc.,NY.

10. Batistella, C. B., Sbaite, P., Wolf Maciel, M.R., Maciel Filho, R. , (2005) Winter, A., Gomes, A., Medina, L., Kunert, R, Heavy Petroleum Fractions Characterization: A New Approach Through Molecular Distillation, $2^{\text {nd }}$ Mercosul Congress on Chemical Engineering \& 4th Mercosul Congress on Process Systems Engineering (ENPROMER 2005), Costa Verde - RJ, Brazil.. 
11. Winter, A., Batistella, C.B., Wolf Maciel, M.R., Maciel Filho, R., Lopes, M. S. Medina, L.C., A True Boiling Point Curve Through Molecular Distillation Using FRAMOL Correlation, Internet resources available at (http://www.nt.ntnu.no/users/skoge/prost/proceedings/icheap8pres07/icheap8webpapers/109\%20Winter.pdf)

12. Randy B., Ian B. , (2006), Sensitivity of Oil Fate Model Predictions to Oil Property Inputs, Can. J Chem. Engng,83, 3.

13. Owen, K. and Coley, T. , (1995), "Automotive Fuels Reference Book", $2^{\text {nd }}$ ed., Warrendale, PA. Society of Automotive Engineers.

14. P. Englezoz and N. Kalogerakis, (2001), Applied Parameters Estimation for Chemical Engineers, Marcel Dekker, INC.

15. Anderson, T. F., Abrams, D. S., Grens, E. A. , (1978), "Evaluation of parameters for Nonlinear Thermodynamic Models", AIChE J., 24, 20, pp 16-21. 


\section{$\underline{\text { Nomenclature }}$}

\section{$\underline{\text { Abbreviations }}$}

ASTM American Society for Testing Materials

FCC Fluidized catalytic Cracking

MOD Mean Overall Deviation

TBP True Boiling Point $\left({ }^{\circ} \mathrm{C}\right)$

LCO Light Cycle Oil

HCO Heavy Cycle Oil

\section{$\underline{\text { Symbols }}$}

V Volume Percent Distilled (\%)

T Boiling Point Temperature of ASTM Distillation $\left({ }^{\circ} \mathrm{C}\right)$

\section{Greek Litters}

$\alpha \quad$ Constant of new Correlation (-)

B Constant of new Correlation (-)

$\Psi \quad$ Dimensionless Temperature (-)

\section{$\underline{\text { Subscript }}$}

i Initial Temperature

$f \quad$ Final Temperature

DM Molecular Distiller 